\title{
Laparoscopic cholecystectomy for double gallbladder
}

\author{
Qingbo Feng ${ }^{1}$, Xiaobing $\mathbf{W u}^{2}$ \\ ${ }^{1}$ Department of Clinical Medicine, The Second Clinical College of Dalian Medical University, Dalian, 116044, China; ${ }^{2}$ Department of Biliary Tract, \\ Eastern Hepatobiliary Surgery Hospital, Shanghai 200438, China \\ Correspondence to: Xiaobing Wu. Department of Biliary Tract, Eastern Hepatobiliary Surgery Hospital, Shanghai 200438, China. Email: wuxb886@163.com.
}

Submitted Oct 12, 2019. Accepted for publication Oct 24, 2019.

doi: $10.21037 /$ hbsn.2019.11.23

View this article at: http://dx.doi.org/10.21037/hbsn.2019.11.23
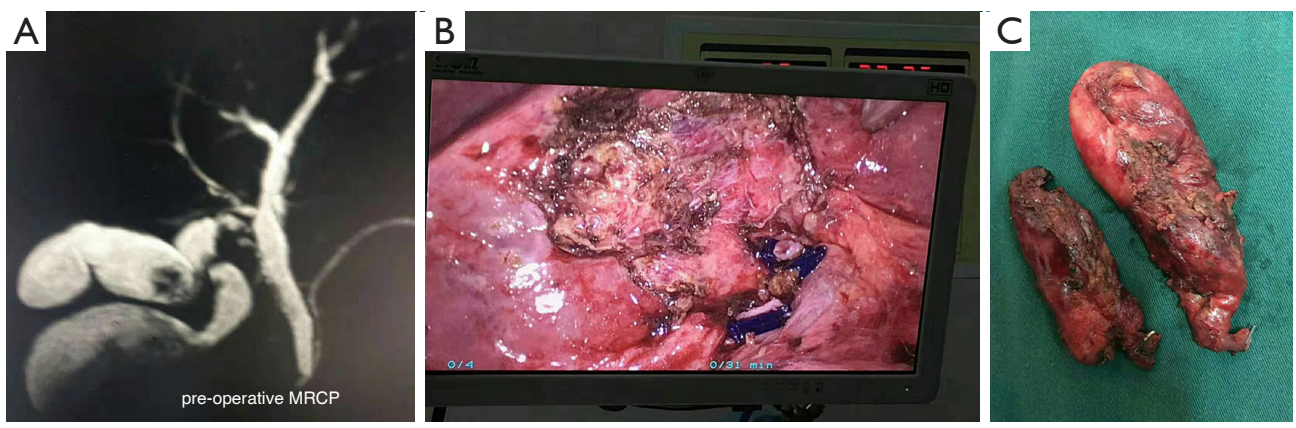

Double gallbladder is an embryological abnormality of relative rarity (1:4,000 human autopsies). Double gallbladder is often discovered accidentally or by complications of gallstones and cholecystitis. Herein, we present an unusual case of double gallbladder in which the cystic duct arises from the common bile duct separately and successfully treated cholecystitis with laparoscopic cholecystectomy.

Magnetic resonance cholangiopancreatography (MRCP) scan confirmed the diagnosis of double gallbladder (H type: two cystic ducts are separately united to common bile duct) (Panel A). Postoperative images of the specimen showing the double cystic duct (Panel B). Postoperative images of the specimen showing the double gallbladder (Panel C).

\section{Acknowledgments}

None.

\section{Footnote}

Conflicts of Interest: The authors have no conflicts of interest to declare.

Ethical Statement: The authors are accountable for all aspects of the work in ensuring that questions related to the accuracy or integrity of any part of the work are appropriately investigated and resolved. Written informed consent was obtained from the patient for publication of this manuscript and any accompanying images.

Cite this article as: Feng Q, Wu X. Laparoscopic cholecystectomy for double gallbladder. Hepatobiliary Surg Nutr 2020;9(1):121. doi: 10.21037/hbsn.2019.11.23 